Open Access

\title{
LMS-enabled blended learning utilization in distance tertiary education: establishing the relationships among facilitating conditions, voluntariness of use and use behaviour
}

\author{
Brandford Bervell ${ }^{*}$ (i) and Valentina Arkorful
}

* Correspondence: b.bervell@ucc. edu.gh

Maths, Science \& ICT Department, College of Distance Education, University of Cape Coast, Cape Coast, Ghana

\begin{abstract}
Distance education has evolved partly through technologies that defined them in the various generations of distance education delivery. However, in the twenty-first century, the use of Learning Management System (LMS) has changed the face of distance education delivery. Even the traditional face-to-face based distance education mode is now adopting the LMS as a mediating technology between instructors and students. However, in the usage of LMS-enabled blended learning, several factors have been cited in the literature as enablers towards actual usage of LMS technology. Factors such as facilitating conditions, voluntariness of use and actual use behaviour have been important in contemporary literature. Despite their importance, the chasm in the literature is the nuances existing in terms of relationships between these three factors. This study fills the gap by defining a model based on the three factors to provide an in depth empirical study on their relationships and how they influence LMS-enabled blended learning uptake of distance education by tutors. The study thus employs a cross country survey to collect data from 267 tutors and offer analysis by way of a Partial Least Squares Structural Equation Modelling (PLS-SEM) approach. The study revealed important relationships among facilitating conditions, voluntariness of use and use behaviour of LMS-enabled blended learning such that facilitating conditions predicted voluntariness of use and actual use behaviour; voluntariness of use determined actual LMS use behaviour for blended learning in distance education. The study finally provided recommendations based on the findings for policy and practice of LMS-enabled blended learning in distance education.
\end{abstract}

Keywords: LMS, Blended learning, Distance education, Facilitating conditions, Voluntariness of use, Use behaviour

\section{Introduction}

Tertiary education is seen as a useful means of preparing human resource for countries all over the world (Bervell \& Umar, 2017a, b; Nyerere et al., 2016). Graduates from tertiary institutions are seen as the basis of a country's formal human resource development for the employment sector (Bervell \& Umar, 2017a, b; Nyerere et al. (2016). In view of this, tertiary education is of high demand worldwide. As a result of this, most tertiary institutions are handicapped in terms of physical infrastructure, personnel and

(c) The Author(s). 2020 Open Access This article is distributed under the terms of the Creative Commons Attribution 4.0 International License (http://creativecommons.org/licenses/by/4.0/), which permits unrestricted use, distribution, and reproduction in any medium, provided you give appropriate credit to the original author(s) and the source, provide a link to the Creative Commons license, and indicate if changes were made. 
other resources to meet the rising demand for tertiary education acquisition (Mohamedbhai, 2011). For instance in Africa, it is reported that the ratio of students to lecturers was 50\% more student per lecturer (Africa American Institute, 2015; Bervell \& Umar, 2017a, b). To remedy the high demand of campus-based tertiary education, most institutions have leveraged on the distance education phenomenon where students are not required to be physically present at all times to study at a confined campus (Anderson \& Dron, 2011; Andersson \& Grönlund, 2009; Mohamedbhai, 2011). Distance education offers a caveat to provide tertiary education both to the working class and qualified applicants who could not gain conventional admission due to institutional resource constraints (Bervell \& Umar, 2017a, b; Mohamedbhai, 2011).

Moore and Kearsley (2004) defined distance education as "teaching and planned learning in which teaching normally occurs in a different place from learning, requiring communication through technologies as well as special institutional organization" (p. 2). However Garrison (2003) proposed a concise definition to the concept of distance education, explaining it as "Distance education is, in the final analysis, education. The only real difference is that the majority of communications between teacher and student is mediated" (p.10). Johnson (2003) however, seems to present a definition that provides some consensus. According to him, "Distance education is defined as simply a form of education in which the learner and instructor are separated during the majority of instruction. But unlike independent or self-directed study, distance education usually implies the presence of an institution that plans curriculum and provides resources and services for its students" (p.1).

All the above definitions emphasize the non-physical presence of students in a brickwalled tertiary institution. However, the phenomenon is not new but has evolved through the generations defined by the type of technologies utilized (Siemens, Gašević, \& Dawson, 2015). For instance Anderson and Dron (2011) explain that the DE mode has metamorphosed through three to four generations beginning from print-based technologies to contemporary internet-based technologies (Aoki, 2012). Accordingly, modern distance education thrives on modern technologies and no distance learning program seems to be feasible without the internet (Ntumy-Coleman, 2011). In terms of internet-based technologies, one of the most common technological platforms altering the delivery of distance education is the Learning Management System (LMS) technology (Mohamedbhai, 2011).

According Sharma and Vatta (2013) "LMS is server-based or cloud-based software programme containing information about users, course and content which provides a place to learn and teach without depending on the time and space boundaries" (p.1). Watson and Watson (2007) and Oakes (2002) had provided similar definitions earlier in the literature. Additionally, Ellis (2009) explains that these systems have the capability of providing the remedy that Sub-Saharan African (SSA) institutions need to avert the challenges of soaring enrolment rates (Bervell \& Umar, 2017a, b).

According to Bervell and Umar (2017a, b), there had been an opinion that, LMS has the potential to widen access, reduce cost and improving the quality of education that will help SSA institutions to meet the growing students population (Andersson \& Grönlund, 2009; Unwin et al., 2010). Based on the advantages of LMS, Farrell and Isaacs (2007) reported that, the acquisition of LMS by higher education institutions in SSA has continued to increase (Bervell \& Umar, 2017a, b). 
As indicated by Bervell and Umar (2017a, b), LMS have been implemented in countries such as Kenya, Tanzania, Uganda, Ghana, Nigeria, South Africa, to mention but a few (Elmahadi \& Osman, 2013; Mayoka \& Kyeyune, 2012; Mtebe \& Raisamo, 2014; Unwin et al., 2010). As far back as 2013, Adkins (2013) indicated that the growth of LMS usage in African higher educational institutions will be at $15 \%$ per annum by the year 2016. Today, most of African higher educational institutions employ LMS for distance education purposes to bridge the gap between instructors and students (Naveh, Tubin \& Pliskin, 2012).

Despite the growing implementation of these e-learning solutions, authors such as Sun, Tsai, Finger, Chen, and Yeh (2008) as well as Hastie, Hung, Chen, and Kinshuk (2010) have all indicated that some failures exist in using LMS. For instance issues such as use behaviour, intentions to use, satisfaction in usage have been deeply expressed in contemporary literature on LMS usage. Other factors such as easiness to use, facilitating conditions towards usage, performance expectations for usage, attitude towards usage, voluntariness of usage etc. have also been indicated in current LMS usage research. Nevertheless, with the ever increasing usage of LMS technology in diverse countries, contexts, types of users (novel or experienced) traditional or innovators, research on LMS knows no bounds. Currently, with strong emphasis on actual use of LMS technology (and not merely intention to use) (Bervell \& Umar, 2018a, b; Martin, 2009; Park, 2009) important factors in current literature such as facilitating conditions; voluntariness of use and actual use behaviour need further consideration in terms of contemporary LMS-related research. The above factors (facilitating conditions; voluntariness of use and actual use behaviour) have not been exhausted in terms of how they relate with each other to induce actual usage of LMS. Individual studies have investigated into the relationship between facilitating conditions and actual use behaviour, but a relationship between facilitating conditions and voluntariness of use as well as voluntariness of use and actual use behaviour is still missing in the literature. Earlier literature by Venkatesh, Morris, Davis, and Davis (2003) suggested different levels of utilization of LMS in both voluntary or mandatory environments and their associations with conditions facilitating actual use behaviour. Chiu and Ku (2015) even suggested studies on levels of voluntariness in terms of actual use behaviour for technology acceptance. Despite this assertion, a definite study defining a model to investigate the tripartite relationships amongst facilitating conditions, voluntariness of use and use behaviour has not been attempted. Thus this study contribute a novelty to current literature by way of a distinct model to unravel the path relationships existing amongst the three variables (facilitating conditions, voluntariness of use and use behaviour) to provide implications for LMS technology use for blended learning in distance based tertiary education.

In view of this the following objectives guided the study:

1. To ascertain whether a relationship exists between facilitating conditions and voluntariness of use of LMS by tutors for distance education delivery.

2. To find out existing relationship between facilitating conditions and LMS use behaviour of tutors for distance education delivery.

3. To unravel the relationship between voluntariness of use and LMS use behaviour of tutors for distance education delivery. 


\section{Towards model development and hypotheses formulation}

The relationships between facilitating conditions, voluntariness of use and use behaviour is explained, theorized and developed into a model with hypotheses formulated further for empirical analysis. The systematic development of the model relationships centres on the relationship between facilitating conditions and voluntariness of use; facilitating conditions and use behaviour; and finally voluntariness of use and use behaviour.

\section{Relationship between facilitating conditions and voluntariness of use}

Facilitating conditions (FC) is defined as the "degree to which an individual believes an organizational and technical infrastructure exists to support use of the system" (Venkatesh et al., 2003, p. 453). The construct is defined in this study as the degree to which course tutors believe that there is the existence and availability of ICT infrastructure, technical support, institutional policy and enthusiastic leadership to support the use of the Fronter LMS. In other acceptance models (TPB/DTPB, C-TAM-TPB) the construct is termed as perceived behavioural control and in IDT as compatibility (Ramayah, 2010). Voluntariness of Use is defined as "the degree to which use of the innovation is perceived as being voluntary, or of free will" (Moore \& Benbasat, 1991, p. 195; Ramayah, 2010). Voluntariness is the extent to which potential adopters perceive the adoption decision to be non-mandated (Agarwal \& Prasad, 1997; Ramayah, 2010).

According to Chiu and $\mathrm{Ku}$ (2015), two unique factors are associated with actual use but in different voluntariness contexts: (1) ease of use (technological context) in mandatory environment (low voluntariness) and (2) organization facilitating conditions (implementation context) in voluntary environment (high voluntariness). Within this study emphasis is made on how facilitating conditions relate with and even determine voluntariness of use. These views were earlier postulated by Venkatesh et al. (2003) and Venkatesh, Brown, Maruping, and Bala (2008).

Accordingly, we leverage on the views of Chiu and $\mathrm{Ku}$ (2015) and Venkatesh et al. (2003) to explain that the presence of enabling conditions such as internet availability, technological support, organizational/management support, motivation etc., has a propensity to enhance individuals' voluntariness towards trying out new technologies. Within this context, tutors will tend to use LMS at will if existing conditions or facilities are favourable towards actual usage. The presence of favourable resources in place towards the use of LMS for distance education delivery will induce the willingness of tutors in using LMS to support their face-to-face tutorials without coercion. In effect, the more facilitating conditions are present towards LMS use, the more it will create the autonomy to use. Thus existing resources necessary for LMS uptake in distance education delivery will positively influence potential users to try out using the system at will for teaching and learning purposes. Accordingly, facilitating conditions will be a prelude to towards voluntariness on the part of tutors to use LMS for andragogical and pedagogical practices. To empirically justify the foregoing arguement, it is hypothesized that:

H1: Facilitating conditions has a positive relationship with voluntariness of use of LMS by tutors. 


\section{Relationship between facilitating conditions and use behaviour}

The effect of facilitating conditions on use behaviour is postulated to be significant (Venkatesh et al., 2003). Venkatesh et al. (2008) indicated that facilitating conditions competes with the other variables in determining actual use behaviour. The resources surrounding the use of an information system, determine the pattern of usage. Course tutors' access to available human and technological assistance towards the system for blended learning has a potential effect on how they will put the system to use. The existence of adequate resources makes it easier for new technological systems to be used (Bervell \& Umar, 2017a, b). This has a rippling effect on how potential users and even experienced users utilize technological systems. In their studies, Attuquayefio and Addo (2014), Tan (2013), Venkatesh, Thong, and Xu (2012) as well as Bervell and Umar (2017a, b), had a positive and significant relationship between the two variables explaining that the environment created within an organizational framework for technology uptake provides a proxy that has a direct control over usage behaviour. The study thus proposes that:

H2: Facilitating conditions has a positive relationship with LMS use behaviour of tutors.

\section{Relationship between voluntariness of use and LMS use behaviour}

Voluntariness represents a state of an individual to act or behave in a certain manner without the element of coercion (Olsaretti, 1998; Olsaretti, 2008). The performance condition (whether mandatory or voluntary) determines the extent to which users put new technology to use (Venkatesh et al., 2003). The UTAUT factor of voluntariness represents the condition under which the intended usage of technology is to be performed. For validation purposes, Venkatesh et al. (2003) identified two possible environments under which performance is expected to operate, namely the mandatory and voluntary settings. The originators of UTAUT postulated and empirically confirmed that, the differing influence in the two performance conditions on technology acceptance cannot be gainsaid. They represent two completely different environments that inhibit or facilitate the effect of certain factors in the UTAUT model.

However, this relationship has never been tested for verification in other studies. This is partly because most studies use this variable as categorical because they are either being tested in a mandatory environment or a voluntary one. Consequently, this study uses an interval scale for the variable to ascertain the condition of usage from tutors. Based on this, the study envisages that the nature of the performance condition contributes to the usage pattern in terms of frequency, regularity or copiousness. This postulation is advanced on the basis of Donaldson (2011) who stated that the more instructors or students are required to use technology devices for pedagogy; the more they will use it. Against this backdrop, the study hypothesizes that:

H3: Voluntariness of use has a negative relationship with LMS use behaviour of tutors.

Based on the hypotheses formulated for this study, a conceptual model to be tested was developed. This is shown in Fig. 1. 


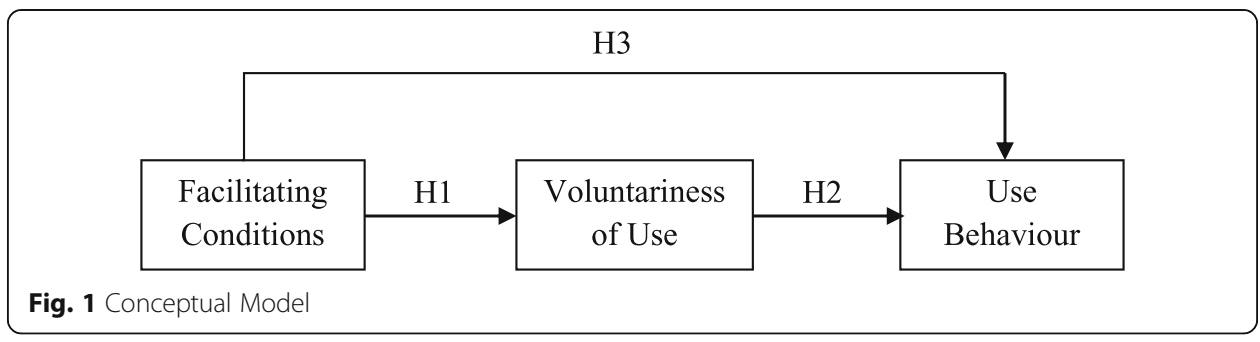

\section{Methodology}

The study applied the quantitative design utilizing the questionnaire for data collection. The questionnaire comprised three sections namely; demographic variable section, independent variables section and dependent variable section. Gender, age, course taught, level facilitated and face-to-face experience formed the demographic variables. In addition, the independent variables were facilitating conditions and voluntariness of use, while the dependent variable was use behaviour. The total number of questionnaire items was 16 . Out of this, five were based on demographic data while the remaining 11 were for both dependent and independent variables measured at an interval scale and anchored on a five point likert scale. Items were modified from Venkatesh et al. (2003) and Venkatesh et al. (2012). Prior to the final items, the original items were validated through expert review and focus group discussions to solve for ambiguity and unclear understanding of the items. After the items were fine-tuned, they were statistically validated through an initial exploratory factor analysis based on a pilot study. Items that loaded below the 0.5 threshold were removed based on recommendations from literature (Hair, Hult, Ringle, \& Sarstedt, 2017; Kline, 2015). Accordingly, two items for facilitating conditions (FC 3 and FC4), and one item for use behaviour (UB 2) were removed. Finally, a confirmatory factor analysis through Partial Least Squares Structural Equation Modelling which forms part of the analysis of this study was run to validate the rest of the items for measurement and structural model analysis. The instrument can be referred from the Appendix. LMS in this context was primarily used for blended learning (discussions after face-to-face sessions), sharing of information and announcements, learning resources, web quests and video-conferencing.

The study targeted a population of 400 tutors who formed part of a pilot group for LMS-enabled blended learning in distance education. These tutors were on the University of Cape Coast distance education programme across study centres in Ghana. They were facilitators for education, Maths \& Science and Business programme at the diploma, postdiploma and postgraduate levels. They were widely distributed across the various study centres of the country. According to Creswell (2009); Creswell and Plano Clark (2007) as well as Walliman (2011) when a population has such a nature, the cross-sectional survey is appropriate. The distribution of the questionnaire by way of cross-sectional survey yielded 267 responses as return rate, representing 66.7\% which was more than half of the total population. According to Krejcie and Morgan (1970), the minimum sample size for a population of 400 is about 196 respondents. This means the sample obtained within this study was an adequate representation of the total population.

The resulting data obtained from the respondents were entered into SPSS software version 21 and further converted into comma separated values (csv) file. This file was then exported into Smart-PLS software version 3.6.2 for the modelling analysis. 


\section{Results}

\section{Demographic analysis}

Demographic analysis of the respondents formed the preliminary analysis. This is shown in Table 1.

From Table 1, respondents comprised 164 males and 103 females representing percentages of $61.4 \%$ and $38.6 \%$ respectively. In terms of the age categories, tutors between 36 and 45 years had the highest frequency of 102 (38.2\%) and those who were 56 years and above constituted the least group, obtaining a tally of 34 (12.7\%). Tutors had faceto-face experience ranging between below 5 years and above 11 years with those between 6 and 10 years having the highest frequency of 112 (42.0\%). The year group who had more than 11 years face-to-face experience were the least among the group. With respect to the courses that tutors taught, tutors who were mainly in education, formed the majority of the group with 136 tally representing $50.9 \%$. The least group was those in maths and science with only 62 frequency representing 23.2\%. Finally, tutors who taught at the diploma level obtained the highest frequency with a percentage of $61.4 \%$ while those at the postgraduate level were the least with only $5.2 \%$.

\section{Measurement and structural model analyses}

In order to provide analyses on the measurement and structural models, the Partial Least Squares Structural Equation Modelling (PLS-SEM) technique was used. The initial assessment of the measurement model required running of the PLS algorithm for confirmatory factor analysis (CFA) on the item loadings that defined the constructs in the reflective model (Hair et al., 2017; Kline, 2015). Results of the PLS algorithm is graphically depicted by Fig. 2.

Table 1 Demographic data

\begin{tabular}{lll}
\hline Profile & Frequency & Percentage \\
\hline Gender & 164 & $61.4 \%$ \\
Male & 103 & $38.6 \%$ \\
Female & & $25.1 \%$ \\
Age & 67 & $38.2 \%$ \\
$(\leq 35)$ & 102 & $24.0 \%$ \\
$(36-45)$ & 64 & $12.7 \%$ \\
$(46-55)$ & 34 & \\
$(\geq 56)$ & & $36.7 \%$ \\
Face to Face Experience & 98 & $42.0 \%$ \\
$(\leq 5$ yrs $)$ & 112 & $21.3 \%$ \\
$(6-10$ yrs $)$ & 57 & \\
$(\geq 11$ yrs) & & $61.4 \%$ \\
Level Facilitated & 164 & $33.3 \%$ \\
Diploma & 89 & $5.2 \%$ \\
Post Diploma & 14 & $23.2 \%$ \\
Post Graduate & & $25.8 \%$ \\
Course Taught & 136 & \\
Education & 62 & \\
Maths \& Science & 69 & \\
Business & & \\
\hline
\end{tabular}


From Fig. 2, all item loadings for the various constructs were higher than 0.5 , satisfying the minimum item loadings as recommended by Hair et al. (2017) and Kline (2015). For instance, items for facilitating conditions loaded between 0.683-0.842; that of voluntariness of use was between $0.631-0.818$; and use behaviour between $0.841-$ 0.899. This implies that the items sufficiently defined the constructs.

\section{Internal consistency measures for measurement model}

In determining the internal consistency of constructs in the model, we used indices such as Cronbach's alpha, composite reliability, rho_A and average variance extracted (AVE) for assessment. This was in line with recommendations from Hair et al. (2017) and Kline (2015). Table 2 shows the results on the internal consistency measures of the reflective model.

From Table 2, Cronbach's alpha values ranged between 0.720-0.894; rho_A values were between 0.736-0.902; composite reliability between 0.801-0.927. The three measures all exceeded the 0.7 recommended threshold (Hair et al., 2017; Kline, 2015). Finally, average variance extracted values were within $0.503-0.760$, all higher than the 0.5 minimum level recommended by Hair et al. (2017). The values obtained from Cronbach's alpha, composite reliability, rho_A and average variance extracted (AVE) for the reflective model shows that the model achieved validity and reliability standards. The overall reliability coefficient for the instrument was 0.797 . This was considered good based on the recommendation by Hair et al. (2017); Kline (2015) and Cronbach (1990).

\section{Discriminant validity}

Discriminant validity which distinguishes each construct in the model from the others was achieved. Henseler, Ringle, and Sarstedt (2015) recommend a higher assessment version of discriminant validity to be the Heterotrait-Monotrait-Ratio (HTMT). In effect, all diagonal loadings on the same construct should be zero (0) while between two different constructs should be less than 0.85 in the stricter sense (Henseler et al., 2015). Results from HTMT in this study are presented in Table 3.

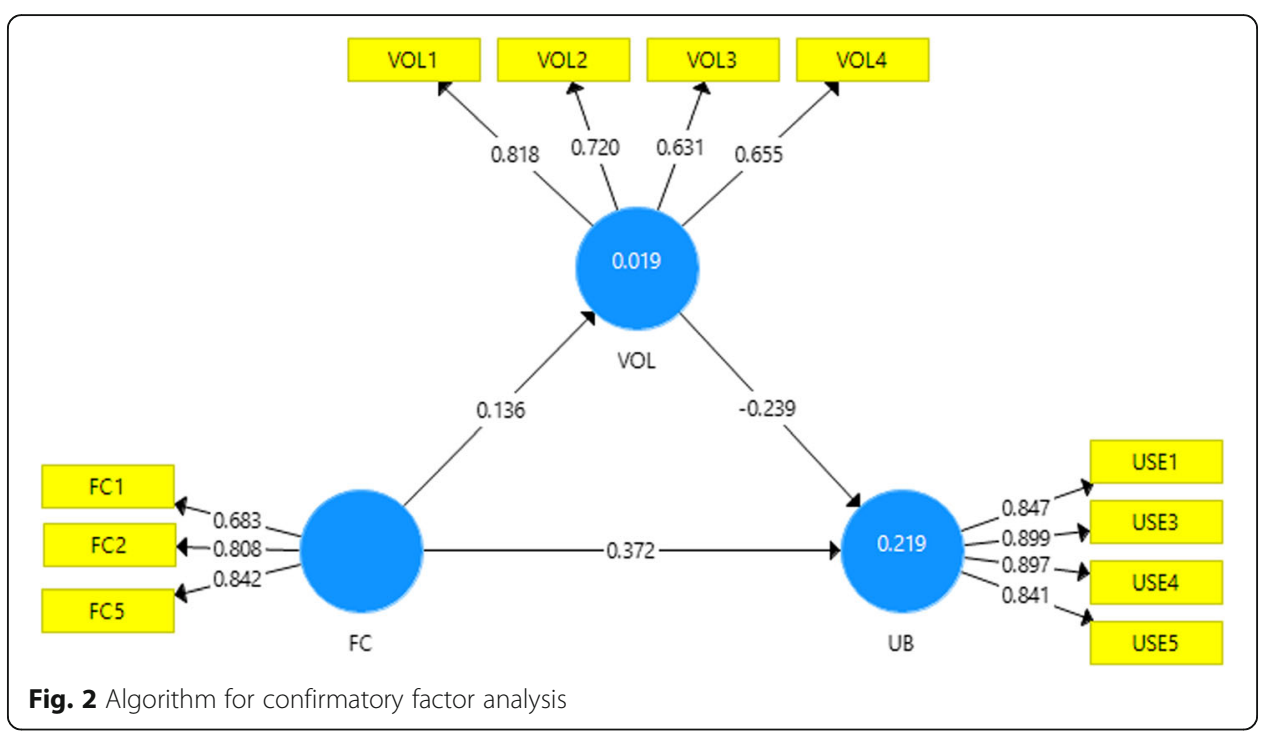


Table 2 Constructs validity and reliability

\begin{tabular}{lllll}
\hline Constructs & Cronbach's Alpha & rho_A & Composite Reliability & Average Variance Extracted (AVE) \\
\hline FC & 0.777 & 0.736 & 0.823 & 0.609 \\
UB & 0.894 & 0.902 & 0.927 & 0.760 \\
VOL & 0.720 & 0.814 & 0.801 & 0.503 \\
\hline
\end{tabular}

From Table 3, the HTMT values ranged between 0.159 to 0.485 . This is an indication that each construct in the model was distinct from the others. Hence, discriminant validity was achieved based on the strict criterion.

\section{Multicollinearity}

Existence of multicollinearity in models seriously affects the validity and reliability of the results obtained by path significance test (Kock \& Lynn, 2012). To verify the existence or otherwise of multicollinearity, the collinearity test on the variance inflation factors (VIF) values is recommended by Kock (2016) and Hair et al. (2017) for reflective models. VIF figures of less than 3.3 represent collinearity-free model (Kock, 2016). Result of collinearity statistics is shown in Table 4.

From Table 4, VIF values were all less than 3.3, thus, ranging between 1.000 to 1.019 for the three constructs. The results of the full collinearity test proved that the model is free from multicollinearity.

\section{Paths analysis}

In order to assess the structural model, the bootstrapping sequence of 5000 samples was utilized in PLS as recommended by Hair et al. (2017) to test for paths significance. Figure 3 depicts the graphical output.

\section{Results of path analysis}

After running the PLS bootstrapping sequence, the tabulated summary of results is shown in Table 5.

From Table 5, results of the paths analysis show that all the three paths tested were significant. This implies that all the hypotheses raised for this study were supported. For instance, the relationship between facilitating conditions and voluntariness of use was positively significant at $(\beta=0.15 ; p<0.05 ; \mathrm{t}=1.796)$ as well as that of facilitating conditions and use behaviour at $(\beta=0.373 ; p<0.01 ; \mathrm{t}=5.003)$. However, the relationship between voluntariness of use and use behaviour was negative but strongly significant at $(\beta=-0.251$; $p<0.01 ; \mathrm{t}=3.378$ ). The sizes of their effect were also favourable for each significant path. This is because, Cohen (1988) recommend effect sizes to be good if they range between 0.02 to 0.35 (Hair et al., 2017). Finally, the unidimensionality of the confidence interval for the three significant paths shows no spuriousity but rather valid and reliable significance.

Table 3 Heterotrait-monotrait ratio (HTMT)

\begin{tabular}{llll}
\hline Constructs & FC & UB & VOL \\
\hline FC & $\mathbf{0}$ & & \\
UB & 0.485 & $\mathbf{0}$ & $\mathbf{0}$ \\
VOL & 0.159 & 0.306 & \\
\hline
\end{tabular}


Table 4 Collinearity

\begin{tabular}{llll}
\hline Constructs & FC & UB & VOL \\
\hline FC & & 1.019 & 1.000 \\
UB & & \\
VOL & 1.019 & \\
\hline
\end{tabular}

The significant results can also be relied upon based on the confidence level of $95 \%$ with a minor error margin of only $5 \%$ according to the statistics obtained from the upper and lower boundaries respectively. Based on the significance of the paths relationships, the final derived model was obtained. This is indicated by Fig. 4.

\section{Discussion}

The findings of the study proved significant for all three hypotheses raised for empirical verification by way of Structural Equation Modelling. The first hypothesis which sought to test the relationship between facilitating conditions and voluntariness of use was significant. This is a novel finding to contribute to existing literature. The finding shows that if facilities are available for LMS-enabled blended learning uptake, it makes usage perception favourable towards easiness (Bervell \& Umar, 2017a, b; Tan, 2013; Attuquayefio \& Addo, 2014). The perceived easiness creates in tutors the willingness to try out LMS technology for their pedagogical and andragogical purposes. The positive relationship existing between facilitating conditions and voluntariness of use indicates that the more facilitating conditions by way of support, internet resources and other forms of motivation, the higher the voluntariness level of tutors to initiate the utilization of learning management systems for blended learning in distance education. This finding is in congruity with the earlier views expressed by Chiu and $\mathrm{Ku}$ (2015); Venkatesh et al. (2003) and Venkatesh et al. (2008) who indicated that organizational facilitating conditions promote high voluntariness. In contexts like this study where tutors are pro- traditional face-to-face instructors, their initial perceptions and willingness towards usage of LMS for distance education delivery is ignited by the presence and availability of resources, support and motivation. This invariably proves that willingness towards the use of LMS and other related technologies

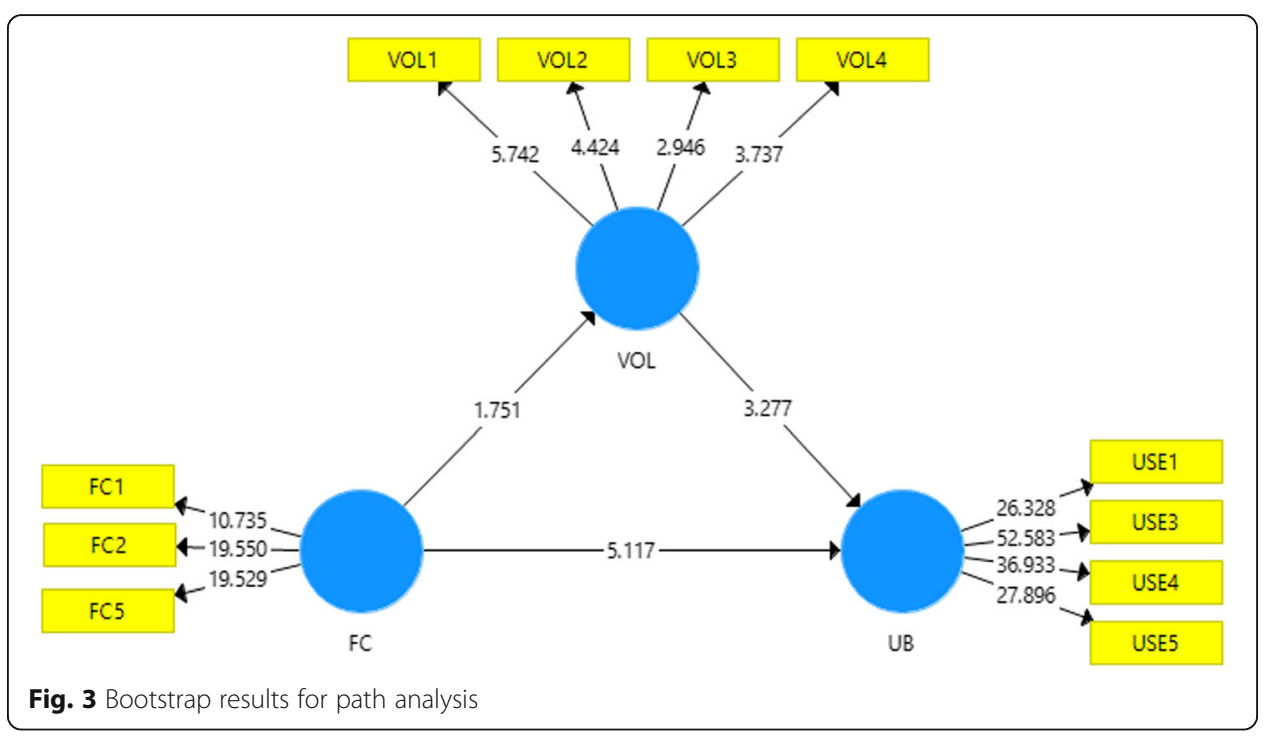


Table 5 Results of paths analysis

\begin{tabular}{lllllll}
\hline Relationship & Beta Value & Std. Error & t- Value & $p$ - Values & $f^{2}$ & $\begin{array}{l}\text { Confidence Interval } \\
\text { LL5\% UL95\% }\end{array}$ \\
\hline FC - > UB & 0.373 & 0.074 & 5.003 & $0.000^{* *}$ & 0.174 & 0.2450 .488 \\
FC - > VOL & 0.150 & 0.076 & 1.796 & $0.036^{*}$ & 0.082 & 0.2620 .330 \\
VOL - > UB & -0.251 & 0.071 & 3.378 & $0.000^{* *}$ & 0.142 & $-0.362-0.141$ \\
\hline${ }^{* *} p<0.01 ;{ }^{*} p<0.05$ supported & & & & & &
\end{tabular}

for pedagogical and andragogical practices can be promoted by facilitating conditions. This finding is further validated by the unidimensionality of the confidence interval values of this relationship. Initial voluntariness of tutors towards the use LMS for their distance education delivery is a positive avenue for them to try out the system.

Course tutors within this study based their actual LMS usage behaviour on the facilitating conditions surrounding usage. Facilitating conditions and use behaviour were significantly related and the relationship was positive. The more conducive course tutors viewed conditions surrounding LMS enabled blended usage, the better their usage behaviour and vice versa. Facilitating conditions here comprised course tutors' assessment of actual accessibility (not mere availability) of resources and conditions deemed as very vital in terms of effective use of LMS. They were likely to put LMS to more usage when facilities and support surrounding usage were favourable and within easy reach. This view supports that of Mtebe and Raisamo (2014); Shin and Kang (2015) and that of Mtebe (2015) who indicated that, the infrastructural resources, technical support and others, have a greater influence on potential users of an information system. Easier access to these resources (human or material) are key, if LMS enabled blended learning is to thrive. Frustrations involved in reaching out for technical assistance or gadgets needed for usage of LMS impede the actual usage of LMS by course tutors. Responses to these conditions showed that course tutors attached importance to them if they were to commit themselves to frequent usage of LMS to successfully complement that of face-to-face interactions. The relationship between enabling conditions and easiness towards use makes LMS useful and motivates tutors to put the system to more usage (Bervell \& Umar, 2017a, b; Park, Nam, \& Cha, 2012; Raman \& Don, 2013; Rogers, 2003). The

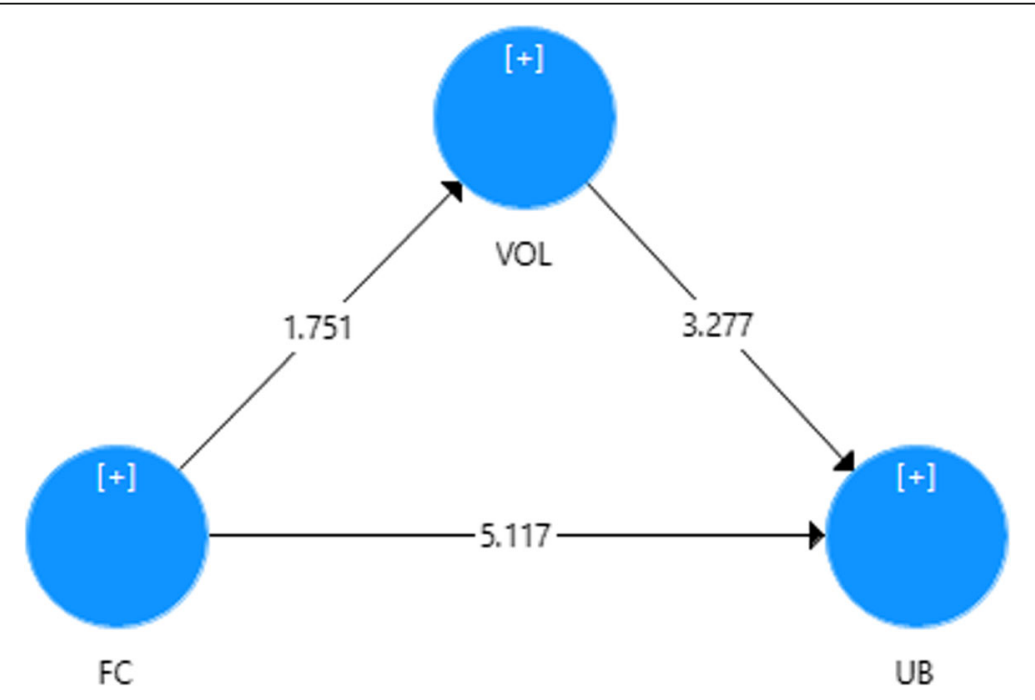

Fig. 4 Derived model 
necessity of facilitating conditions in determining actual usage is also present in studies such as Attuquayefio and Addo (2014); Azlina, Razak, and Abdulla (2013) as well as Bervell and Umar (2017a, b) which are in line with the current study but does not share parallelism with that of Birch and Irvine (2009).

The relationship between voluntariness of use and use behaviour was tested with the notion that the environment set up for uptake of LMS technology by course tutors has an influence on actual use, especially with course tutors coming from the background of traditional face-to-face. Normally, this variable was a moderator to social influence towards intentions (Venkatesh et al., 2003). However, within this study, the relationship was tested to verify how the nature of usage environment (voluntary or mandatory) could determine how course tutors used LMS. Within the literature, Venkatesh et al. (2003) had expressed views about different levels of usage within the two different use environments, although they did not test the relationship.

Surprisingly, the relationship between the two variables was very significant. Voluntariness of usage environment had a direct effect on usage behaviour of course tutors. Importantly, the relationship was negative; indicating that course tutors were unlikely to employ the LMS technology to use if the usage environment set by authorities is a totally voluntary one. This was anticipated because of the number of years course tutors have practiced traditional face-to-face and so even though the attitude towards LMS was positive within this study, the likelihood of not using it in the face of little difficulties encountered, is greater. The descriptive statistics of tutors' responses largely indicated that their usage condition was voluntary. Voluntary environment of use for course tutors at this early stage of acceptance is likely to slow down actual use to support face-to-face. The more mandatory the LMS usage environment, the greater the propensity that course tutors will put the system to use and become more familiar with it, in terms of utilization for blended learning in distance education. This is particularly evident if majority of course tutors do not have LMS specific previous experience backed by difficulty with the tendency of adaptation to change in terms of technological innovation. The reason being that tutors have been pro traditional in their delivery of distance education practices. As such, leaving the use of LMS for blended approach as a free will reduces the element of change needed to propel the blended mode. This supports earlier stance by Donaldson (2011) that requiring instructors and students to use mobile learning, will make them use mobile devices and other technologies for learning purposes. This approach is similar for LMS-enabled blended learning since it also incorporates a technology to dispense a certain mode of learning. Although other studies did not model this relationship, coupled with its absence in all technology acceptance models, Richardson, Neiger, Jensen, et al. (1990) suggest that "even under large amounts of pressure, humans quickly adjust to their best state" (as stated in Zhu, Huang, Hu, \& Li, 2016, p. 1). The authors' view is better related to the model of human adaptation to transition (Schlossberg, 1981). This makes the relationship very important in this study for LMS uptake in distance education, especially at this initial stage of acceptance.

\section{Implications for theory}

The findings in this study have implications for theoretical considerations in technology acceptance research. To begin with, voluntariness of use has a direct significant relationship with behavioural intention when constructed as an interval scale variable. This 
result provides an indication that the scale at which the variable is constructed determines its role either as a moderating variable or predictor variable. The new relationship proves that the level of voluntariness for LMS usage or any system's uptake determines the extent to which the system will be patronized. For theoretical model formation, this study establishes a relationship between the level of voluntariness and use behaviour. This is contrary to the relationships of this variable existing in the UTAUT and TAM $2 \& 3$ models which merely makes the variable a moderating one.

Additionally, the relationship between facilitating conditions and voluntariness of use implies that the level of facilitating conditions influence the level of voluntariness of use for technology systems. This relationship can be included in models such as UTAUT and TAM $2 \& 3$ to further test their importance in acceptance studies of technology uptake. This is because individuals may decide to voluntarily take up the use of technology systems when facilitating condition are in place, especially for experienced users and continuous usage.

\section{Implications for practice}

The utilization of LMS for blended learning in distance education within this context should not be made overly voluntary at the earlier stages of implementation but complemented with motivating factors such as promotion credits, resource incentive for copious users of the LMS, as well as institution of awards for best online facilitators at the end of the academic calendar.

Management in promoting the initial voluntary levels of usage of LMS by tutors should put facilities in place first before commencing the implementation of the use of LMS-enabling blended learning. The initial voluntariness or willingness provides a positive outlook for LMS uptake by tutors for distance education delivery.

Complementary enabling conditions such as management support, technical teams' support, reliable internet supply, motivation etc., ought to be readily meted out to tutors and made accessible to promote frequent use of LMS for blended learning purposes in distance education. In support of this, management together with technical teams should also ensure the possibility of LMS being accessible at all times to boost the confidence of tutors in terms of the functionality of the system which enhances usage.

\section{Recommendation for future studies}

It is recommended that this study is conducted on experience users of LMS to verify the relationships investigated in this study.

In addition this study recommends that future studies look at the relationships in the context of mandatoriness.

Furthermore, we recommend an exact replication of this study to confirm or otherwise the findings, since it is a pioneer study.

Another study is required to replicate this current study from the perspective of distance students and parallel the findings with that of the tutors.

Finally, it is recommended that the study should also be conducted on experienced users of LMS for blended distance education delivery.

\section{Limitations of the study}

The study was limited to only tutors without considering the perspective of students. 
The study was limited to novel users of LMS in distance education delivery and so the result cannot be generalized to experienced users of LMS.

The study environment was largely voluntary and so results may differ in a mandatory perceived environment of LMS usage.

\section{Conclusion}

The study pioneered an empirical testing of a model that depicts the relationships that exist among facilitating conditions, voluntariness of use and use behaviour of LMS by tutors in delivering a blended form of distance education. It was discovered that important relationships exist between facilitating conditions and voluntariness of use; facilitating conditions and use behaviour; as well as voluntariness of use and use behaviour of tutors in their quest to utilize learning management systems to deliver a blended mode of distance education. These important relationships have affordances towards the theorization, policy and practice on how LMS could be implemented and used in higher education for blended mode of distance education delivery.

\section{Appendix}

Table 6 Scale Items

S/ Items on Voluntariness of Use

1. I feel I am being forced to use the online learning system in addition to face to face instruction.

2. I think any online learning system usage to support face-to-face distance education delivery should be made optional.

3. Although it might be helpful using the online learning system to support face to face teaching and learning, it is not made compulsory.

4. The college does not require me to use the online learning system in addition to the existing face to face teaching and learning mode.

S/ Items on Facilitating Conditions

$\mathrm{N}$

1. I have the resources necessary to use the online learning system in addition to face to face.

2. I have the knowledge necessary to use the online learning system to support face to face.

3. The online learning system is compatible with other systems I use to complement face to face. (Removed)

4. When I am in difficulty in utilizing online learning system for online learning activities to support face to face, the system's support team is available for assistance. (Removed)

5. The management has provided enough support towards the use of the online learning system together with face to face interaction.

S/ Items on Use Behaviour

$\mathrm{N}$

1. I used the online learning system for online forum discussions after face to face.

2. I used the online learning system for uploading and sharing learning resources before and after face to face sessions. (Removed)

3. I used the online learning system for announcements on teaching and learning activities before and after face to face.

4. I used the online learning system for video-conferencing to support face to face interaction.

5. I used the online learning system for providing links to additional online resources for students after face to face sessions. 
Acknowledgments

The authors would like to express their special thanks to the distance education tutors that participated in the survey.

\section{Authors' contributions}

Both $\mathrm{BB}$ and $\mathrm{VA}$ formulated the conceptual model; developed the hypotheses for the study and the methodology. BB run the analysis and interpreted the results. Both BB and VA did the write up (discussions) and the their implications for theory, policy and practice. Both BB and VA read and approved the final manuscript.

\section{Funding}

This research was funded by the University of Cape Coast [TDS/109/.2/97].

\section{Availability of data and materials}

Data and materials will be provided by the corresponding author upon request.

\section{Competing interests}

The authors declare that they have no competing interest.

Received: 25 October 2019 Accepted: 5 February 2020

Published online: 17 March 2020

\section{References}

Adkins, S. S. (2013). The Africa market for self-paced eLearning products and services: 2011-2016 forecast and analysis Available at: http://www.ambientinsight.com/Resources/Documents/AmbientInsight-2011-2016-Africa-SelfPacedeLearningMark-et-Abstract.pdf.

Africa American Institute (2015). A report card on the progress, opportunities and challenges confronting the African education sector State of Education in Africa Report 2015.

Agarwal, R., \& Prasad, J. (1997). The role of innovation characteristics and perceived voluntariness in the acceptance of information technologies. Decision sciences, 28(3):557-582.

Anderson, T., \& Dron, J. (2011). Three generations of distance education pedagogy. The International Review of Research in Open and Distance Learning, 12(3), 80-97 Retrieved from http://www.irrodl.org/index.php/irrodl/article/view/890/1663.

Andersson, A., \& Grönlund, Å. (2009). A conceptual framework for e-learning in developing countries: A critical review of research challenges. The electronic Journal of information systems in developing Countries, 38(1), 1-16.

Aoki, K. (2012). Generations of distance education: Technologies, pedagogies, and organizations. Procedia - Social and Behavioral Sciences, 55, 1183-1187.

Attuquayefio, S. N., \& Addo, H. (2014). Using the UTAUT model to analyze students' ICT adoption. International Journal of Education and Development using Information and Communication Technology, 10(3), 75.

Azlina, A., Razak, F., \& Abdulla, W. (2013). Assessing the effects of UTAUT and self determination predictor on students continuance intention to use student portal. World Applied Sciences Journal, 21, 1484-1489.

Bervell, B., \& Umar, I. N. (2017a). Validation of the UTAUT model: Re-considering non-linear relationships of Exogeneous variables in higher education technology acceptance research. Eurasia Journal of Mathematics, Science and Technology Education, 13(10), 6471-6490

Bervell, B., \& Umar, I. N. (2017b). A decade of LMS acceptance and adoption research in sub-Sahara African higher education: A systematic review of models, methodologies, milestones and main challenges. Eurasia Journal of Mathematics, Science and Technology Education, 13(11), 7269-7286.

Bervell, B., \& Umar, I. N. (2018a). Utilization decision towards LMS for blended learning in distance education: Modeling the effects of personality factors in exclusivity. Knowledge Management \& E-Learning, 10(3), 309-333.

Bervell, B., \& Umar, I. N. (2018b). Blended learning or face-to-face? Does tutor anxiety prevent the adoption of learning management systems for distance education in Ghana? Open Learning: The Journal of Open, Distance and e-Learning, 119. https://doi.org/10.1080/02680513.2018.1548964.

Birch, A., \& Irvine, V. (2009). Preservice teachers' acceptance of ICT integration in the classroom: Applying the UTAUT model. Educational Media International, 46(4), 295-315. https://doi.org/10.1080/09523980903387506.

Chiu, T. M., \& Ku, B. P. (2015). Moderating effects of voluntariness on the actual use of electronic health records for allied health professionals. JMIR Medical Informatics, 3(1), e7.1-e7.10.

Cohen, J. (1988). Statistical power analysis for the behavioral sciences. Mahwah: Lawrence Erlbaum.

Creswell, J. W., \& Plano Clark, V. L. (2007). Designing and conducting mixed methods research. Thousand Oaks, CA: SAGE Publications.

Creswell, J. W. (2009). Research Design Qualitative, Quantitative, and Mixed Methods Approaches (3rd ed.). Thousand Oaks, CA Sage Publications.

Cronbach, L. J. (1990). Essentials of psychological testing, (5th ed., ). New York: Harper \& Row.

Donaldson, R. L. (2011). Student acceptance of Mobile learning. In Unpublished PhD Thesis. Florida: Florida State University.

Ellis, R. K. (2009). Field guide to learning management systems, ASTD learning circuitsRetrieved 7th June, 2017 from http:// www.astd.org/ /media/Files/Publications/LMS_fieldguide_20091.pdf.

Elmahadi, I., \& Osman, I. (2013, May). A study of the Sudanese students' use of collaborative tools within Moodle learning management system. In 2013 IST Africa Conference \& Exhibition (1-8). US: IEEE.

Farrell, G., \& Isaacs, S. (2007). Survey of ICT and education in Africa: A summary report, based on 53 country surveys, (pp. 0-74). Washington, DC: Information Development and ICT Series, World Bank. Retrieved June 16, 2017 from http://www. Infodev.org/en/Publication.353.html.

Garrison, R. D. (2003). Quality and access in distance education: Theoretical considerations. In D. Keegan, Theoretical principles of distance education (2005). US: Routledge.

Hair, J. F., Hult, G. T. M., Ringle, C. M., \& Sarstedt, M. (2017). A primer on partial least squares structural equation modeling, (2nd ed., ). Thousand Oaks: Sage. 
Hastie, M., Hung, I.-C., Chen, N. S., \& Kinshuk (2010). A blended synchronous learning model for educational international collaboration. Innovations in Education and Teaching International, 47(1), 9-24.

Henseler, J., Ringle, C. M., \& Sarstedt, M. (2015). A new criterion for assessing discriminant validity in variance-based structural equation modeling. Journal of the Academy of Marketing Science, 43(1), 115-135.

Johnson, J. L. (2003). Distance education: The complete guide to design, delivery and improvement. New York: Teachers College Press.

Kline, R. B. (2015). Principles and practice of structural equation modelling methodology in the social sciences, (4th ed.. ). New York: Guilford Publication.

Kock, N. (2016). Advantages of nonlinear over segmentation analyses in path models. International Journal of e-Collaboration (JeC), 12(4), 1-6.

Kock, N., \& Lynn, G. S. (2012). Lateral collinearity and misleading results in variance-based SEM: An illustration and recommendations. Journal of the Association for Information Systems, 13(7), 546-580.

Krejcie, R. V., \& Morgan, D. W. (1970). Determining sample size for research activities. Educational and Psychological Measurement, 30(3), 607-610.

Martin, J. (2009). Developing course material for online instruction of adults. Journal of Online Learning and Teaching, 5(2), 364

Mayoka, K., \& Kyeyune, R. (2012). An analysis of e-learning information system adoption in Ugandan universities: Case of Makerere University business school. Information Technology Research Journal, 2(1), 1-7.

Mohamedbhai, G. (2011). Higher education in Africa: Facing the challenges in the 21st century. International Higher Education, 63, $20-21$.

Moore, G. C., \& Benbasat, I. (1991). Development of an instrument to measure the perceptions of adopting an information technology innovation. Information systems research, 2(3):192-222.

Moore, M. G., \& Kearsley, G. (2004). Distance education: A systems view, (2nd ed., ). Belmont: Wadsworth Publishing.

Mtebe, J. (2015). Learning management system success: Increasing learning management system usage in higher education in subSaharan Africa. International Journal of Education and Development using Information and Communication Technology, 11(2), 51.

Mtebe, J. S., \& Raisamo, R. (2014). A model for assessing learning management system success in higher education in subSaharan countries. The Electronic Journal of Information Systems in Developing Countries, EISDC, 61(7), 1-17.

Naveh, G., Tubin, D., \& Pliskin, N. (2012). Student satisfaction with learning management systems: a lens of critical success factors. Technology, Pedagogy and Education, 21(3):337-350.

Ntumy-Coleman, R. K. (2011). Assessing the adoption of e-learning in Ghanaian universities: Case of some Ghanaian universities. Unpublished Master's Thesis. Sweden: Luleå University.

Nyerere, J., Mfune, O., Fuh, D., Sulemana, N., Mutisya, E., Yiran, G., ... Odingo, A. (2016). The role of higher education in building a sustainable African society. AJSD, Special Edition, 4(3), 17-37.

Oakes, K. (2002). E-learning: LCMS, LMS- They're not just acronyms but powerful systems for learning. Training \& Development, 56(3), $73-75$.

Olsaretti, S. (1998). Freedom, force and choice: Against the rights-based definition of voluntariness. Journal of Political Philosophy, 6(1), 53-78.

Olsaretti, S. (2008). Debate: The concept of voluntariness—A reply. Journal of Political Philosophy, 16(1), 112-121.

Park, S. Y. (2009). An analysis of the technology acceptance model in understanding university students' behavioral intention to use e-learning. Journal of Educational Technology \& Society, 12(3), 150

Park, S. Y., Nam, M. W., \& Cha, S. B. (2012). University students' behavioral intention to use mobile learning: Evaluating the technology acceptance model. British Journal of Educational Technology, 43(4), 592-605.

Raman, A., \& Don, Y. (2013). Preservice teachers' acceptance of learning management software: An application of the UTAUT2 model. International Education Studies, 6(7), 157-160.

Ramayah, T. (2010). The role of voluntariness in distance education Students' usage of a course website. Turkish Online Journal of Educational Technology-TOJET, 9(3), 96-105.

Richardson, G. E., Neiger, B. L., Jensen, S., et al. (1990). The resiliency model. Journal of Health Education, 21(6), 33-39.

Rogers, E. M. (2003). Diffusion of innovations. New York: Free Press.

Schlossberg, N. K. (1981). A model for analyzing human adaptation to transition. The counselling psychologist, 9(2), 2-18.

Sharma, A., \& Vatta, S. (2013). Role of learning management systems in education. International Journal of Advanced Research in Computer Science and Software Engineering, 3(6), 997-1002.

Shin, W. S., \& Kang, M. (2015). The use of a mobile learning management system at an online university and its effect on learning satisfaction and achievement. The International Review of Research in Open and Distributed Learning, 16(3), 110-130.

Siemens, G., Gašević, D., \& Dawson, S. (2015). Preparing for the digital university. Retrieved September, 1, 2018.

Sun, P. C., Tsai, R. J., Finger, G., Chen, Y. Y., \& Yeh, D. (2008). What drives a successful e-learning? An empirical investigation of the critical factors influencing learner satisfaction. Computers in Education, 50(4), 1183-1202.

Tan, P. J. B. (2013). Applying the UTAUT to understand factors affecting the use of English e-learning websites in Taiwan. SAGE Open, 3(4), 2158244013503837.

Unwin, T., Kleessen, B., Hollow, D., Williams, J., Oloo, L. M., Alwala, J., ... Muianga, X. (2010). Digital learning Management Systems in Africa: Myths and realities. Open Learning: The Journal of Open and Distance Learning, 25(1), 5-23.

Venkatesh, V., Brown, S. A., Maruping, L. M., \& Bala, H. (2008). Predicting different conceptualizations of system USE: The competing roles of behavioral intention, facilitating conditions, and behavioral expectation. MIS Quarterly: Management Information Systems, 32(3), 483-502.

Venkatesh, V., Morris, G. M., Davis, B. G., \& Davis, F. D. (2003). User acceptance of information technology: Toward a unified view. MIS Quarterly, 27(3), 425-478.

Venkatesh, V., Thong, J. Y., \& Xu, X. (2012). Consumer acceptance and use of information technology: Extending the unified theory of acceptance and use of technology. MIS Quarterly, 36(1), 157-178.

Walliman, N. (2011). Research methods: The basics. Abingdon: Routledge.

Watson, W. R., \& Watson, S. L. (2007). An argument for clarity: What are learning management systems, what are they not, and what should they become? TechTrends, 51(2), 28-34.

Zhu, G., Huang, C., Hu, B., \& Li, G. (2016). Autonomy in individual behavior under multimedia information. Multimedia Tools and Applications, 75(22), 14433-14449.

\section{Publisher's Note}

Springer Nature remains neutral with regard to jurisdictional claims in published maps and institutional affiliations. 